A CASE ILLUSTRATING

THE

\title{
PHYSIOLOGY AND PATHOLOGY
}

\section{OF THE \\ CERVICAL PORTION OF THE SYMPATHETIC NERVE.}

\author{
$\mathbf{B Y}$ \\ WILliam OGLE, M.D. Oxon., F.R.C.P., How. Sec., \\ ASSISTANT-PHYSICIAN TO, AND LECTURER ON PHYSIOLOGY AT, ST. GEORGE's \\ HOSPITAL.
}

Received Jan. 29th.-Read March 23rd, 1869.

OUR knowledge of the functions of the cervical sympathetic is derived almost exclusively from experiments on animals, man himself having furnished very few data, pathological or experimental. I cannot, therefore, but hope that the case which I have now to bring forward will be found one of great interest; for the symptoms observed in it will, $I$ think, satisfy physiologists that the sympathetic nerve had either been cut through on one side of the neck, or, if not actually divided, yet so disorganised as to amount practically to the same thing.

It will perhaps be well before I narrate my case, to recall briefly the chief observations which have hitherto been made on this nerve in man.

So far as $I$ have been able to ascertain, there are only two 
cases on record in which the symptoms observed during life led to the conclusion that the cervical sympathetic had been severed.

In one case, a surgeon in removing a tumour from the right side of the neck apparently divided the nerve. Next day the face on that side was deeply congested, and marked with well-defined patches of a violet red. The right pupil was contracted; the conjunctiva normal. No observations were made as to the temperature. ${ }^{1}$

The second case is of more importance. An American soldier in the course of the late war was shot through the neck with a bullet. Two months after he had been thus wounded he came under the notice of Messrs. Mitchell, Morehouse and Keen, who have recorded his case in their work on gunshot wounds (p. 39). The pupil of the right eye was very small, that of the left eye unusually large. There was slight but distinct ptosis of the right eye, and its outer angle seemed to have dropped a little lower than the inner angle. The ball of the right eye seemed smaller than that of the left, and its conjunctiva was somewhat redder. The pupil was not only contracted but slightly deformed, oval rather than round. In a dark place, or in half lights, the difference in the pupils was best seen; but in very bright light the two pupils became nearly of equal size. The left eye watered a good deal, but had the better vision, the right eye having become myopic. He complained of frontal headache, of loss of memory, and of red flashes in his right eye when exposed to the sunlight, and also, after long exposure, in the left eye. With all this there were no abnormal retinal appearances. The patient's face presented a curious appearance after walking in the heat. It became distinctly flushed on the right side and pale on the left. The flush extended to the middle line, but was less definite as to its limits on the chin and lips than above these points. Unfortunately no thermometric examination was made, while the man was thus flushed with exertion; but careful examination made during repose, showed no difference in the heat of the two sides

$$
1 \text { 'Gazette des Hôpitaux,' No. 64, } 1868 .
$$


within the mouth or ear. The man improved under a tonic treatment. The eyes became less sensitive, the pupils more nearly alike, and the line of the lid straighter. In three months' time nearly all his peculiar symptoms had disappeared, and he returned to his duty.

By the side of this case may be set the following experiment.

In 1859, a woman was beheaded at Wurzburg. As soon as the axe had fallen, the head was wrapped in hot cloths and carried off to the neighbouring theatre of anatomy, where Prof. Wagner with a number of physiologists and students was awaiting it. ${ }^{1}$ Eighteen minutes only had elapsed since the moment of decapitation, when a magneto-electric current was applied to the left cervical sympathetic at the point where it had been exposed by the axe, an inch and a quarter below the superior ganglion. Some four or five seconds passed, and then the left eye slowly opened and its pupil was seen to dilate widely. Already a year earlier Prof. Wagner had made a similar experiment on the head of another criminal and with similar results.

If to this experiment of Professor Wagner and to the two cases previously cited be added numerous instances of ptosis and of altered pupil coincident with cervical tumours, ${ }^{2}$ and possibly due to pressure on the sympathetic, we have all the main observations made on the action of this nerve in the human body. To these scanty data, I would now contribute the following addition.

J. R - served his full time as soldier. During that time he drank hard and lived loosely, and suffered in consequence from delirium tremens and repeated chancres. Nearly three

I Cf. Brown-Séquard's 'Journ. de Physiol.,' iii, 174.

2 For a collection of such cases see a paper by my namesake Dr. John Ogle, in 'Med.-Chir. Trans.', vol. xli. In one of these cases, described by Dr. Gairdner, there was not only contracted pupil but " a remarkable irregularity of temperature-cold sweats followed by flushing, accurately limited to that half of the face on which the pupil is affected." Dr. Gairdner has seen another similar case. (Cf. p. 413.) 
years ago a hard lump formed on the right side of his neck, and not long afterwards the whole arm on that side became enormously swollen. This swelling soon disappeared, but the lump on the neck grew larger and suppurated; and thus an abscess was formed which took many months to heal. While this was going on, about two years ago, his wife noticed that his right eye appeared smaller than the left one; and also that the right ear was redder than its fellow. On looking at the glass he found that such was the case, and so it has remained ever since. He soon also noticed that the right side of the face, and especially the right ear, felt hotter to him than did the left; and this he says is more particularly the case when he washes his face with cold water in the morning. These symptoms concerned him so little, that he has never mentioned them to a doctor, and they were only noticed by accident while he was under treatment for certain nocturnal pains, which yielded readily to iodide of potassium. ${ }^{1}$

On examining the patient I found a large puckered scar on the right side of the neck, running in a transverse direction and extending very nearly the whole way from the clavicle in front to the median line behind. In the neighbourhood of the scar some hard nodules, doubtless indurated glands, could be felt, and there was some dulness on percussion under the clavicle. The formation in the neck had evidently compressed the large vessels of the arm, for no pulse could be felt either in the brachial or in the radial artery. The blood, moveover, returned from the arm by the superficial veins, which were large and tortuous, and ran from the arm over the upper front of the thorax till they dipped down out of sight above the clavicle. The arm itself was well nourished and fairly muscular. The swelling of the arm at the time when the lump was forming in the neck had doubtless been odema caused by pressure on the vessels, and its subsidence was due to the establishment of new

1 J. R- was originally a patient of Dr. Dickinson's. He came into my hands while I was doing Dr. Dickinson's hospital work in his absence. I obtained Dr. Dickinson's permission to make use of the case. 
channels for the ingress and egress of the blood. The pulse could be felt distinctly in the carotid artery.

The palpebral fissure of the right eye was much narrower than that of the left. This was partly due to a lowering of the "upper lid, partly to an elevation of the lower one, and perhaps rather more to the latter than to. the former cause. Notwithstanding the apparent ptosis there was perfect voluntary control over the upper lid. The patient when asked to open his"eyes widely, raised the two upper lids equally well. There,was, however, even then a marked difference in the size of the two palpebral fissures, owing to the different levels at which the lower lids stood. The eyelids also followed perfectly the motion of the eyeball when the patient was directed to look upwards or downwards. ${ }^{1}$ Excepting the narrowing there was no deformity in the fissure, and no drooping of the outer angle, such as was observed in the American soldier, and has been frequently seen as a result of section of the cervical sympathetic in animals.

The right eyeball was somewhat retracted; that is, it lay deeper in its cavity than did the eye on the other side. The muscular motions of the eye were perfect.

The right pupil was very much contracted. When the patient looked towards the light, the diameter of this pupil was scarcely more than half that of the left; when the eyes were shaded the difference was still greater. The contracted pupil reacted to the light, but slowly and within very narrow limits. When a solution of atropine was dropped into the eyes, both pupils dilated largely, and the inequality of size entirely disappeared. It returned so soon as the effect of the atropine had passed off. With calabar bean both pupils contracted considerably. The right was reduced to a mere

1 I mention this fact because of its possible bearing on the theory which attributes "exophthalmous goitre" to some lesion of the cervical sympathetic. In that curious disease the upper eyelid does not follow the upwards and downwards motion of the globe, or follows it imperfectly, as was first pointed out by V. Gräfe. V. Gräfe thinks that goitrous exophthalmia may be distinguished by this symptom from other forms of exophthalmia. Cf.' Archiv für Psychiatrie, \&c.,' 1868, p. 444. 
point or little more; the left, though much contracted, was not so small as this.

The conjunctiva in both eyes was somewhat congested, and that of the right eye rather more, but not much more, than that of the left.

On ophthalmoscopic examination, which Mr. Power was good enough to make for me, it was found that the media were perfectly clear. There was slight central excavation of the optic disc in either eye ; and in both the apparent outer portion of the disc was pinker than the inner portion. There was no visible difference in the size of the central vessels nor in the general vascularity of the two retinæ. The sight was good, and equally good on the two sides.

The ear on the right side was much redder than the ear on the left; and sensibly warmer to the hand. The skin of the right cheek, and the skin just above the right eye were also sometimes, but not always, pinker than the corresponding parts on the left. This seemed especially the case when the man was slightly flushed with gentle exercise; though as will be seen presently it was not the case when violent exercise was taken. The right temporal artery was more prominent than the left; but no difference of colour was visible on the two sides, excepting in the parts already mentioned. The difference of colour in the two ears, and of heat as measured by the hand, was much increased by applying ice to them for a short time. Both ears became paler and colder from this application, but the left much more than the right. The patient was misled by this increasing difference of temperature, to say several times during the refrigeration that his "right ear was getting hotter and hotter." So also he stated that his right ear was always hottest when he washed his face with cold water in the morning. When hot water was applied for a time to the ears, both became redder and warmer, and all apparent difference between them-as measured by touch and sight-disappeared. Of the repeated thermometric observations made later on this man, it will be enough to give a single sample; for, excepting under the conditions to be presently mentioned, the result was always 
the same; that is, the right side of the face was invariably hotter than the left. Here then are the results obtained one morning when the man was in fairly good health, and had not taken exercise. ${ }^{1}$

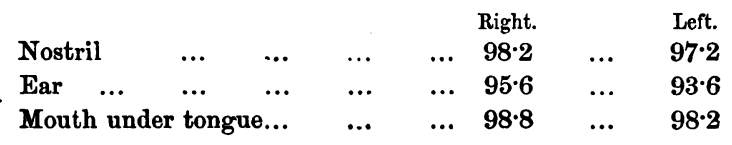

Notwithstanding the greater vascularity and the higher temperature of the right side, the man asserted that he only sweated on the left side of his face; that when he walked in the wind his left eye alone watered; that though abundant mucus was discharged from his left nostril none ever came from his right one; and lastly that the right side of his mouth often felt drier to him than the other, and that so dry altogether was his mouth that he was obliged for comfort to take acid drops so as to promote the flow of saliva. This seemed so strange, and so opposed to all that one would have expected $a$ priori, that at first $\mathrm{I}$ thought the man must be mistaken. I got him, however, to put on an extra coat and to run round the park till he was thoroughly heated. On his return I found the left side of the face, head, and neck, bathed in sweat; the whiskers and hair on that side were dripping, and the shirt-collar soaked through. The corresponding parts on the right side were perfectly dry. The line of demarcation between the wet and the dry skin was exactly in the centre of the forehead in front, and ran vertically over the crown of the head to the centre of the neck behind. I wiped the face till it was dry, and in a few minutes the sweat again appeared on the left side; and with the same rigid line of demarcation. Both legs and both sides of the body were sweating equally. The thermometer now gave the following results :

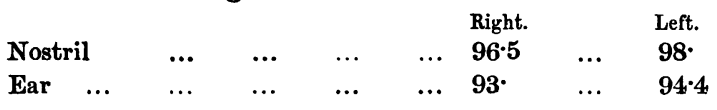

1 The temperature of the nostrils was taken inside the cavity. The temperature of the ears by placing the bulb of the thermometer between the lobule and the side of the head, and keeping the lobule closely against it. 
It thus appeared that violent exertion had inverted the relative conditions of the two sides of the face. When the man was at rest the right side was the warmer of the two; when he had exerted himself it was the colder. This was the more extraordinary, because, as I have before mentioned, a slighter amount of excitement seemed often to increase the vascularity of the right side and to deepen the contrast between it and the left.

I repeated the above experiment on more than one occasion, and always with a similar result. Invariably after violent exertion the left side of the face was the hotter; while invariably, with one single exception, the right was the hotter when the man had remained quiet, and had not been exposed to any extraordinary conditions. The single exception was this. I found one morning the two ears equally warm, the thermometer giving $95^{\circ}$ for each. The pulse was rapid, the skin hot, and the man complained of feverishness, for which he accounted, and probably correctly, by his having sat up the greater portion of the preceding night. The man's health has been so equable that I have had no opportunity yet of repeating this observation. So far, however, as it goes, it would seem to show that feverishness tends to act in this man in the same way as violent exertion and to invert the thermometric conditions of the two sides.

I was anxious to know what would be the effect of exposure to a high temperature. I therefore got the man to take a Turkish bath. He remained in the hot-air chamber for an hour and a half. During the whole of.this time not a drop of moisture appeared on the right side of his face, head, or neck, though the corresponding parts on the left and all the rest of his body were bathed in sweat.

As my patient was thus accurate in his statement as to the sweating, and is an intelligent straightforward man, we may, In think, assume that his further statements as to the secretions of the eyes, nostrils, and salivary glands were also accurate. My attempts to verify these came to little. On holding ammonia in front of his face, at an equal distance from the two eyes, lachrymation was produced on both sides. 
It began, however, in the left eye, and seemed more copious on that side than on the right. When the surface of the tongue was moistened with ether abundant salivation was produced, and I am unable to say that it was more copious on one side than the other. Both ears contained much cerumen, and, as far as I could judge, in equal amounts.

The remaining symptoms presented by this man were of comparatively slight importance. There was no increase of sensibility, special or general, on the right side; no apparent nutritive alterations; no change of shape in nostril or in mouth, such as Bernard ${ }^{1}$ has noticed in some animals. The pulse was rapid, never below 90 . There was a little husky cough, but the voice and respiration were quite normal. There was occasional frontal pain, of no great severity, on the right side. The intelligence was good, though the patient said that lately his memory was weaker than it had been.

Such were the symptoms. To what were they due? I think there can be no doubt that they were the result of lesion of the right cervical sympathetic, and of a lesion which was equivalent to division of that nerve. For all the phenomena can be explained on that hypothesis, and as far as I can see, on no other. At the same time that I was watching this man I had under observation some rabbits in which the cervical sympathetic had been cut on one side. The symptoms presented by these rabbits-the well-known symptoms described by Bernard, Brown-Séquard, and others-were identical with those presented by this man, and rabbits or man served equally well to demonstrate to a class the effects of this operation. The symptoms might, indeed, be explained theoretically by supposing disease to have implicated that portion of the spinal cord from which the cervical sympathetic has its origin. But such disease would inevitably have betrayed itself in the course of two years by other signs of spinal disease. It will be remembered, also, that the symptoms dated from a time when there was a deep abscess in the neck. I suppose that this abscess had eaten through, or, at any rate, thoroughly disorganised the nerve, and this

$$
1 \text { 'Système nerveux,' t. ii, } 473 .
$$


probably not only at one small spot, but for some little distance, so as to prevent reunion. That the consequent hyperæmia should have persisted so long is somewhat remarkable: for, as a rule, this symptom is of comparatively short duration in animals. In rabbits, for instance, according to Bernard, ${ }^{1}$ the hyperæmia is scarcely discernible after fifteen or eighteen days from the time of section. It is very temporary also in the horse and in the guinea-pig. In the dog it lasts longer, but seldom for more than six weeks or two months. Still these results are not invariable. I have now a rabbit in which the hyperæmia still persists, though in diminished intensity, eleven weeks after section; and on one occasion Schiff saw the hyperæmia persist in a dog two entire years without any great diminution. ${ }^{2}$

I pass on now to make a few remarks on the more notable symptoms presented by my patient, and to compare them with the results obtained experimentally in animals. And first of the eye.

The eyeball was somewhat retracted, that is, lay deeper in its socket than did the eye on the opposite side. This is a phenomenon which always occurs after section of the cervical sympathetic in mammalia; while the contrary movement, viz. protrusion, follows on galvanisation of the nerve. In this man the retraction was certainly as considerable as that which occurs in rabbits. I insist upon this, because in the experiment made by Wagner on the criminal's head, no motion of the eyeball occurred on galvanisation of the sympathetic. In the case of the American soldier, it is not expressly stated that the eye was retracted, but inasmuch as the eyeball seemed smaller on the affected side than on the sound one, it is very probable that there was, in reality, some retraction.

The retraction and protrusion of the eyeball have been variously interpreted by physiologists. The real explanation, however, seems to be that which was originally put forward ${ }^{3}$

\footnotetext{
1 'Syst. Nerv.,' ii, 492.

2 Schiff, 'Leçons sur la Digestion,' i, 258.

3 Brown-Séquard's 'Journ. de Phys.,' 1860, p. 176. “Sur un muscle lisse de l'orbite de l'homme et des mammifères."
} 
by $\mathrm{H}$. Müller on theoretical and anatomical grounds, but which has recently received its experimental confirmation at the hands of M. Prevost. ${ }^{1}$ Müller discovered, in the orbital cavity of mammalia, a funnel-shaped layer of smooth muscular fibres, provided with elastic tendons (musculus orbitaris), and so arranged as to be capable by their contraction of propelling the eyeball forward in its socket. This smooth muscle receives filaments from the cervical sympathetic. M. Prevost has recently experimented upon this muscle, and found that direct galvanisation of it in dogs causes protrusion of the eyeball, as Müller had supposed. ${ }^{2} \mathrm{He}$ also found that when this muscular layer was completely divided, no motion of the eyeball ${ }^{3}$ could any longer be produced by galvanising the sympathetic. The proof then is complete, that it is through the agency of this muscle that the protrusion is effected by the sympathetic. The retraction of the eyeball is produced partly by the relaxation of this funnel-shaped muscle, and more completely, in such animals as possess it, by the striated retractor muscle. Now in the human ${ }^{4}$ orbit

1 " Recherches sur le ganglion sphenopalatin,” ‘Archives du Physiol.,' 1868, p. 221, \&c., and 'Comptes Rendus,' 1867, p. 849.

2 In one particular Prevost's experiments are in opposition to Müller's views. Müller thought that the sympathetic filaments which govern the orbital muscle reached it through the sphenopalatine ganglion. Prevost has shown that this is not the case. For protrusion of the eyeball is produced by galvanising the cervical sympathetic, even when the sphenopalatine ganglion has been previously destroyed.

3 That the membrana orbitaris was muscular was the opinion of older anatomists, though this opinion had been discarded long before Müller's discovery. Neither was it a novelty to attribute the protrusion of the eyeball to this membrane. Thus in Wagner's 'Elements of Comp. Anat.' (Tulk's translation, p. 25) we find, "It is only in the Apes that the eye is situated, as ir. Man, in a complete bony cavity closed both from without and within; in all the rest of the mammalia, and also in the Makis, the orbital and zygomatic spaces blend upon the sides of the skull. Both spaces are, nevertheless, separated by a peculiar membrane, which is called the orbital membrane, and was formerly regarded incorrectly as muscular; it arises from the periosteum, lines the orbits funnel-wise, and consists partly of elastic tissue. It seems to act as an antagonist to the retractor muscle of the globe of the eye, protruding or pushing the eyeball forward so soon as the action of that muscle ceases."

4 This smooth orbital muscle of the human eye was discovered, indevoL. LII. 
a similar orbital muscle is found, but a much less perfect one than exists in those mammalia whose orbital cavity is less completely surrounded with bone. In man moreover there is no retractor muscle. It is, therefore, only natural to expect that the motion of the globe forwards and backwards should be less strongly marked in man than in many animals. Whatever, however, may be the case as regards protrusion, my case shows that a considerable retraction can occur.

The palpebral fissure was considerably narrowed. This is a constant result of section of the sympathetic in mammals, while galvanisation of the nerve as constantly produces dilatation of the fissure. The fissure was narrowed also in the case of the American soldier; while, in the experiments of Wagner, the closed eye was made to open by galvanising the nerve. As these motions are produced by the agency of the sympathetic we cannot attribute them to the striated levator palpebræ muscle, for there is no known instance in our body of the motions of striated voluntary muscle being directly governed by sympathetic fibres. Müller' consequently explains the phenomena by the contraction and relaxation of certain smooth muscle fibres, which are found in both lids, but in greater abundance in the lower than in the upper one; an explanation which is in accordance with the fact that the diminution of width is due rather more to a raising of the lower lid than to a depression of the upper one. It is consistent also, as Wagner observed, ${ }^{2}$ with the fact that the opening of the lids which follows on galvanisation of the sympathetic is produced slowly, and persists for some little time after the galvanisation has been discontinued. These characters belong to the contraction of smooth and not to that of striated muscular tissue.

pendently of Müller's previous discovery of it, by Prof. Turner, and described by him in the 'Natural Hist. Review,' January, 1862, "On a Non-Striped Muscle connected with the Orbital Periosteum of Man and Mammals." It has been more recently investigated by M. Sappey, and described by him in detail, 'Comptes Rendus de l'Acad. des Sciences,' 1867, p. 675.

1 Brown-Séquard, 'Journ. de Phys.,' iv, 279.

2 Ibid., iii, 176. 
The pupil was contracted. This again is a well-known result of section of the cervical sympathetic, and has also been seen repeatedly in man when there was reason to suspect pressure on the nerve. There was, however, in my case one peculiarity which deserves notice. When a solution of atropine was dropped into the eyes, both pupils dilated fullythe right as much as the left-and all inequality of size vanished. In experiments made on animals this has not been the case. The pupil on the side of the section has been found to enlarge, but not so widely as the pupil on the opposite side. ${ }^{1}$ Why there should be this difference in the cases of man and of animals I am unable to conjecture, but of the fact there can be no doubt. I repeated the experiment more than once, and each time with the same result. It has been argued by various writers that the dilatation by atropine of the pupil, after it has been contracted by section of the sympathetic, is a proof that atropine acts not simply by paralysing the circular fibres of the iris, but by stimulating its radial fibres. But an objection to this argument has always been possible hitherto. For it might be urged that, as the dilatation was only slight, and not nearly so complete on the injured as on the uninjured side, it was simply due to the elasticity of the iris, which was now no longer kept in check by the sphincter muscle. No such objection can be made in the case of my patient. The dilatation was as complete on the one side as on the other, and so great that it is out of the question to refer it to mere elasticity.

Before leaving the eye, I would make a few remarks on the condition of the retina. This was examined with the greatest care many times, and no hyperæmia whatsoever could be detected in it. The vascularity was not greater in one retina than in the other. Neither was there any morbid sensitiveness to light. On the contrary, the man was remarkably tolerant of long-continued ophthalmoscopic examination, and the tolerance was as great in one eye as in the other. This, I think, disposes of the opinion held by some

1 Valentin, 'Versuch einer physiol. Pathologie der Nerven," ii, 156, and Ludwig, ‘Lehrbuch der Phys.,’ p. 282. 
physiologists, that the section of the nerve "operates simply by exaggerating for a time the sensibility of the retina, as it does that of the integument, and that the partial closure of the eyelids and pupil is a secondary consequence of that condition."l For here there was neither hyperæmia nor exaggerated sensibility; yet the lids were partially closed and the pupil contracted. There may, indeed, have been hyperæmia at an early period, when the lesion was recent; but if so it had entirely passed away, and with it should have gone the other symptoms, were they really dependent thereon. On searching through books to find what has been the observed condition of the retina in animals, after section of the cervical sympathetic, I was surprised to find no information whatsoever. ${ }^{2}$ The great experiments were made before the ophthalmoscope came into use; and the hyperæmia of the retina has been rather a matter of inference than of direct observation. It must not, however, be assumed that because there is hyperæmia of the skin, of the conjunctiva, and of other parts, that there is also necessarily hyperæmia of the retina. For Schiff has shown that by no means are all the vaso-motor nerves of the head contained in the cervical sympathetic ; and thus it might be that those of the retina passed by some other channel. I thought it well, therefore, to examine into this. Mr. Power carefully examined for me the ophthalmoscopic appearances in two rabbits, in which the cervical sympathetic had been divided on one side. In both there was considerable hyperæmia of the retina on the side of the section. How rapidly the hyperæmia occurs is shown by the following observation on a third rabbit. This animal was put under chloroform, and the nerve cut on one side of the neck. The animal died from chloroform, without recovering consciousness. On dissecting out the eye, the retina on the side of the section was found quite pink from the dilatation of its vessels, while the retina

1 Dalton's 'Physiology,' 3rd ed., p. 523.

2 An ophthalmoscopic examination was made in the case of the American soldier quoted at the beginning of this paper, and no abnormal retinal appearances discovered. 
of the opposite eye was colourless. Either, then, there is a difference between man and rabbits, as regards the vasomotor arrangements of the retina, or, as is perhaps more probable, retinal hyperæmia had been present in my patient at an earlier period, but had subsided in the course of the two years which had elapsed since the nerve lesion.

So much for the phenomena presented by the eye. It remains to consider the condition of the rest of the face.

The right side of the face was redder and hotter than the left. This at least was the state of things when the man was in good health and tranquil. The symptom is, of course, accounted for by the palsy of the circular muscles of the blood-vessels and the consequent hyperæmia. That the difference should have increased with slight excitement is not surprising. The excitement would cause increased heart action, and the slightly enlarged vessels of the right side would admit more blood than the sound vessels of the left. What, however, is astonishing is that violent exertion should have had just the opposite effect, and should have inverted the relative conditions of the two sides, raising the left, or sound side, to a higher temperature than the injured side, and inducing secretion on the former alone.

Strange, however, as this seems, it is after all what occurs in animals after unilateral section of the cervical sympathetic, as was discovered not very long ago by Schiff. ${ }^{1}$ Schiff had cut the cervical sympathetic on one side in a dog. The wound had healed some time, and the dog was in good health, and presented no other notable symptom than the permanent hyperæmia of the ear on the side of the old operation. One day, while the dog was in this condition, Schiff happened to examine its ears after it had been running about and had got much heated. To his surprise, he found the ear on the sound side, which was usually the colder and the paler, now the more vascular of the two ; when the dog had cooled down, the original condition returned, and the ear on the side of the section became again the warmer. This

1 Schiff, op. cit., p. 259. 
observation led to experiments, which showed that any form of general excitement, such as exercise, emotion, or fever, inverts the thermometric and vascular conditions of the two sides, after unilateral section of the cervical sympathetic.

I have since made numerous experiments in imitation of those of Schiff, and with results corroborative of his statement. Some few of these I will describe briefly.

Exp. 1.-The cervical sympathetic was cut on the right side in a rabbit. The ordinary symptoms resulted. The right ear was much the more vascular and the hotter to the touch. Two days after the operation, and while this condition remained, I placed the rabbit in a hot-air chamber, keeping the temperature at about $120^{\circ} \mathrm{F}$. The rabbit remained in this for more than an hour. It was then in a state of considerable excitement, and its heart was beating with much greater rapidity than at the commencement of the experiment. Its left ear was now found to be $1 \frac{1}{2}^{\circ} \mathrm{F}$. hotter than the right one. The experiment was repeated several times, the rabbit being replaced in the intervals in the hot chamber, and each time the result was the same; the difference of temperature varying from $1 \cdot 2^{\circ} \mathrm{F}$. to $2 \cdot 4^{\circ} \mathrm{F}$., but being invariably in favour of the left or non-operated side.

Exp. 2.-The right cervical sympathetic was cut in a rabbit. The right ear after this was $8^{\circ} \mathrm{F}$. hotter than the left. Twelve days later the difference between the two ears was so slight that it was barely appreciable to the hand. The rabbit was now hunted about a room, till it was very excited and hot. The left ear after this was found to be nearly $2^{\circ} \mathrm{F}$. hotter than the right one. I then applied ice to the ears, taking great care that both should be exposed equally to its action. The temperature sank rapidly, and the right ear was found to be $3^{\circ} \mathrm{F}$. hotter than the left one.

Exp. 3.-The left cervical sympathetic was cut in a rabbit, and the ordinary results obtained. Some days afterwards the left ear was still more vascular and warmer than the right. The ears were pulled and rubbed briskly. After this the right ear was found to be much the more vascular of the two, and no difference of temperature was perceptible to 
the touch. This inverted condition of the ears lasted for a very short time.

Similar results were obtained by Schiff by injecting pus into the veins, and producing artificial fever. This I have not repeated. But it will have been noticed in the history of my patient that on one occasion I found his left ear equally hot with the right one, and this though he had not taken any violent exercise. He had, however, sat up half the preceding night, and was in a feverish condition. Had the febrile condition been more severe, very probably the left ear might not merely have equalled, but have surpassed the right in warmth.

Besides heat, violent exercise, and fever, there are other conditions which can invert the relative conditions of the two ears after unilateral nerve section. Thus Bernard found that when chloroform was given to dogs, the ear on the non-operated side became the warmer at the moment of insensibility. $^{1}$ I have twice repeated this experiment on rabbits, but without a similar result. The operated side in such case retained its excess of warmth over the other. It may be that dogs and rabbits differ in this respect, or it may be that the rabbits I used were exceptional. For no one can make many experiments on the sympathetic in rabbits, without finding that there are considerable differences in the phenomena presented by different individuals of the species, and especially that the phenomena vary with the length of the ears. ${ }^{2}$

Again, in rabbits a temporary inversion may occur independently of any apparent external influence or internal fever, as the following observation shows.

Exp. 4.-I cut the left cervical sympathetic in a rabbit with long pendent ears. Shortly after the section the usual results were noted in the left eye, and the left ear was much more vascular and $8.5^{\circ} \mathrm{F}$. hotter than the right one.

1 'Syst. Nerv.,' ii, 503.

2 It would appear from an observation made by Kussmaul (' Einfluss der Blutströmung,' \&c., 42) that even the colour of rabbits is a matter not to be neglected in experimental physiology. 
Two days later I was surprised at finding the conditions inverted. The right ear was much the more vascular, and sensibly warmer to the hand. I imagined that the wound must have inflamed, and that the inversion was the result of fever. The wound, however, seemed perfectly healthy, and no febrile symptoms could be detected. After examining the wound, I again looked at the ears, and to my astonishment the conditions were again reversed. The left had again become the more vascular and the warmer. Soon there was another change, and at last it became quite apparent that, while the vascular and thermometric condition of the left or operated side was almost, though not quite, stationary, the condition of the right or non-operated ear was one of irregular oscillation; its vessels alternately dilating and contracting in periods, which varied from twenty seconds to three minutes. When its vessels were at their maximum dilatation, their calibre was greater than that of the vessels on the opposite side; when they were at their minimum, their calibre was much smaller. These oscillations of vascularity were accompanied by corresponding oscillations of temperature. The thermometer in this ear was never at rest, whereas, in the opposite ear, the mercury rose gradually to a maximum, and then remained practically stationary.

Doubtless the vascular oscillations ${ }^{1}$ of the right ear were nothing more than the normal oscillations of calibre which occur in the arteries of the rabbit's ear independently of the heart's action, and which were first observed by Schiff. The only peculiarity was that in this long-eared rabbit the oscillations were more extensive and less rapid than usual. The section of the sympathetic on the left side had interfered with the normal oscillations on that side, but had not completely stopped them. The residue of normal action was probably due to the fact that the vasal nerves of the rabbit's ear do

1 I noticed in this case that, when the arteries were widely dilated on the sound side, a smart rap caused them instantly to contract very considerably. When, on the other hand, they were contracted, a similar stimulation caused them to dilate. That is, the stimulation changed the condition of the vessel whatever it might be. 
not all pass by the cervical sympathetic, but are in part contained in the great auricular nerve, partly also in a branch derived from the fifth nerve.

Observations very similar to the one just given have been made by Schiff, and a strong argument founded on them in favour of his theory of active vascular dilatation. ${ }^{1}$

It would appear, then, that both in man and animals section of the cervical sympathetic not only interferes with the contraction of the arteries on the side of the section, but also in some way or other prevents their full dilatation; assuming, of course, that the temperature is an indication of the arterial condition, and that it rises and falls with the calibre of the vessels. It would appear that the vessels on the side of the section oscillate in size within very narrow limits, their minimum width being greater and their maximum width narrower than that of the vessels on the sound side.

A certain explanation of this curious phenomenon is yet to be found. Schiff's interpretation is as follows. He holds that in the cervical sympathetic are contained not only nervefibres whose office it is to cause arterial contraction, but others also, in smaller numbers, which when stimulated produce vascular dilatation. It is to the section of the former more abundant ones that the ordinary result of hyperæmia is due ; and it is to the section of the latter that the inability of the arteries to dilate fully is assigned.

To those who already admit the existence of nerves which actively dilate blood-vessels, Schiff's explanation will approve itself. I for one must confess that I see no way of accounting for some of the phenomena described by Schiff, but by admitting the existence of such active dilators. At the same time it is plain that the explanation, so far as I have yet given it, does not cover all the facts. It will account for the copious sweating which immediately follows section of the nerve in the horse; but it will not at the same time explain the utter inability to sweat which occurred at a later period in my patient. So also it will account for the hyperæmia 
which immediately follows section, but will not explain the marked diminution of that hyperæmia which occurs within a day or two of the section, and before there has been time for any nerve regeneration.

The explanation, however, may be extended so as to include these outlying facts, by taking into consideration certain results of the section of motor nerves. ${ }^{1}$ When the motor nerves of a striated muscle are divided, there is at first a slight and transitory increase of extensibility in the muscular tissue. This is, however, soon followed by a change in the opposite direction. There is a loss of extensibility, and this loss goes on increasing until it finally reaches a maximum where it becomes stationary. Later on, the muscle is found not only to have lost extensibility, but actually to have become shortened or contracted. These changes are most strongly marked in the muscles of birds, ${ }^{2}$ but they are apparent enough in the case of man. Thus, Messrs. Mitchell, Morehouse, and Keen, ${ }^{3}$ in their work on the wounds of nerve-trunks, notice that when a muscle begins to suffer in its nutrition from nerve-lesion, the first effect is the production of a flabby and relaxed condition; but that sooner or later this relaxation gives way, and in many instances is succeeded by a condition of shortening or contraction, which may or may not be associated with a corresponding degree of atrophy. The facial muscles furnish us I think occasionally with an illustration of the same kind. When the facial nerve is cut or injured, a striking deformity is, as we all know, at once produced. The muscles of the uninjured side prevail over their flabby and relaxed opponents, and draw the angle of the mouth and the features generally awry; and this is the case even when the face is at rest. Not rarely the nerve-lesion is a permanent one; but in such cases it will often be found that the distortion does not remain unchanged. In time it begins to decrease, and the face gradually recovers almost entirely its normal aspect, so long as it is at rest. All voluntary power

1 Cf. Schiff, op. cit., p. 258.

2 Cf. Vulpian, 'Syst. Nerv.,' p. 265.

${ }^{3}$ Cf. op. cit., p. 72. 
over the muscles being permanently gone, this recovery can only be accounted for by supposing that the palsied muscles have gradually contracted, and offer a greater resistance to extension from the sound muscles of the opposite side. This process of contraction may go on to such an extent as to cause the palsied muscles to prevail over the sound ones. I have at present a patient in whom this has occurred. He has long suffered from facial paralysis of the left side. At first the mouth was, as usual, pulled over to the right. Gradually this deformity diminished. The face became straight; and now, the palsy still persisting, the mouth is actually drawn slightly to the left or paralysed side.

Now, we have only to suppose that similar physical changes are produced in the muscular coat of the arteries when its motor nerves are divided, and the difficulties which met us before vanish. 'The gradual diminution of hyperæmia, and the suppression of sweat some time after the section will find an adequate explanation in the altered state of the vessels, which are then no longer capable of sufficient extension. On the other hand, the excessive hyperæmia and the copious sweating which are the earlier consequents of the section, will coincide with the period of augmented extensibility-a condition which will assist the palsy of the circular muscles in producing a wide vascular dilatation.

Let me now apply this explanation to the case of my patient. I imagine that when the nerve-lesion first occurred the hyperæmia of the right side was much more strongly marked than it is at present, and most probably extended at that period to the retina. I imagine also that in those early days there was increased activity of secretion on the side of the nerve-lesion $;^{1}$ but that gradually owing to the contraction of the palsied muscular coat the hyperæmia has been reduced to its present insignificant amount; and that in some parts of the face this contraction has so entirely

1 I could not actually find out when the suppression of sweat began in this man. He said that he had only noticed it lately, but could not fix the date for me with any greater precision. It could hardly have existed long without attracting his attention. 
balanced the vascular palsy that in them there is no hyperæmia left, though at the same time their inability to sweat shows that they are in some abnormal condition. Heat, exercise, febrile excitement generally, are unable to produce any great increase of vascularity, and so any secretion, on the affected side, partly because of the unyielding nature of the arterial walls, partly because the actively dilating nerve-fibres have been severed. The effect of these stimulants, which act with full force on the vessels of the opposite side, is therefore to invert the conditions of the two sides as regards vascularity, and consequently as regards temperature.

Before I leave this part of my subject, I would point out that, if there really be produced in palsied arteries such a physical alteration as that which $I$ have mentioned, it may perhaps help us to reconcile the discordant results of experiment and of pathological observation as regards the temperature of limbs, the nerves of which have been divided. In experiments such limbs are found-as we should expect $\grave{a}$ priori - to have their heat increased ; in pathological cases they have been found to have their heat notably lowered. It may perhaps be that in experiments the temperature has been tested at an early period, in pathological cases at a later period after the nerve-lesion. A physiologist will be almost certain to make his examination within a very short interval after he has cut the nerves; and, on the other hand, a surgeon will be unlikely to make any special observation of the condition of the temperature for some time. Even should he do so, the results will seldom be of use as regards this question, for most probably the injury which has divided the nerve will also have divided the artery, and will thus interfere in another way with the blood supply. Again, there may very possibly be inflammation about the wound, or still more probably the patient may be in a state of febrile excitement, and I have already pointed out that fever or excitement is in itself suffcient to invert the relative conditions of two parts, one of which has its vasal nerves cut, while the other retains them uninjured; and thus we have a second very possible cause of 
deception. In corroboration of these remarks, I may quote the following passage from Mr. Hutchinson's instructive paper on the results which follow injuries to nerve-trunks.

"Next to the loss of sensation, respecting which we need say nothing, we have as the chief results of nerve section a diminution of temperature. It is to be noted that none of my cases were accurately observed soon after the accident, most of them not until the wound was healed. Many conditions make trials of temperature at early periods after the injury liable to mislead. Such for instance as the fact that the vessels as well as the nerves are usually cut, that inflammation is in progress at the wound, and that the part is protected by dressings."

Dr. Handfield Jones, in an interesting paper on 'Trophic Nerves, ${ }^{2}$ has suggested another interpretation of the refrigeration after nerve section. He supposes, as I have done, that there is at first dilatation of the arteries and elevated temperature, the vasal nerves being cut as well as the rest; but that the sympathetic fibres, being of simpler structure than the tubular ones, are regenerated long before these latter, so as to resume their control over the vessels; and that when regenerated they are kept in a state of constant irritation by the cicatrix of the skin and subjacent tissues.

To this explanation there appear to me to be several serious objections. In the first place, the refrigeration lasts sometimes without apparent improvement for an indefinite period. Can we admit of an active contraction in the vessels kept up for year after year without any intermission by irritation of the vasal nerres? Is not long-continued active contraction inevitably succeeded sooner or later by the contrary condition of relaxation?

Secondly, what real reason is there to suppose that the vasal nerves are regenerated after section sooner than the tubular nerves? It is true that there is a certain resemblance in general aspect between sympathetic fibres and simple

1 'London Hosp. Reports,' iii, 321.

2 'St. George's Hosp. Reports,' vol. iii, 94. 
fibroid tissue, as ${ }^{1}$ Dr. Handfield Jones points out, and that fibroid tissue can be formed with great readiness and rapidity. But surely fibroid tissue and sympathetic fibres, differing as they do in their properties and functions, are not to be looked on as one and the same thing in virtue of this superficial similarity; and the facility of formation of the one is no ground for assuming a similar facility in the formation of the other.

Again, how is it, if these nerve-fibres are so readily regenerated, that when the cervical sympathetic has been cut the alterations in the pupil often remain for an indefinite period without change, though the hyperæmia sooner or later diminishes or even altogether disappears? If the nerve be reformed the two effects of its section should alike and simultaneously disappear on its reformation. As it is, the one effect is permanent, the other temporary. ${ }^{2}$

The objections which I have urged against Dr. H. Jones' explanation of the refrigeration appear to me to have much force. At the same time I would guard myself against being supposed to fancy that the other explanation which $I$ have advanced is free from objections and difficulties, or that it can claim to be more than a mere hypothetical solution of the problem.

Be the true explanation of this matter what it may, it is at any rate clear that the phenomena presented by my patient were practically the same as result in animals from section of the cervical sympathetic. Neither dogs nor rabbits sweat visibly, so that 1 cannot illustrate from experiments on them the unilateral suppression of sweat which occurred in this

1 Cf. op. cit., p. 102 and 96.

2 A similar objection, it is plain, may be made against the other explanation which I have advanced. It may be asked, how is it that, after section of the sympathetic, loss of extensibility, and gradual contraction occur in the palsied muscular coat of the arteries, and yet do not occur in the similarly palsied dilator of the iris? The answer to this would be that the conditions in the two cases are different. The dilator of the iris is kept from undergoing the changes in question by the constant stretching to which its fibres are sub. jected from the unpalsied sphincter; while there is no such counteracting influence at work in the case of the arterial muscles. 
man. Still, that anything which prevents the due dilatation of vessels should also interfere ${ }^{1}$ with secretion is only what experience teaches us to expect, It appears to me not impossible that something of the kind occurred in the case of the soldier whose case I gave at the beginning of this paper, at any rate so far as his lachrymal glands were concerned. For in the short account given of his symptoms it is mentioned that " the left eye waters a good deal," though the nerve lesion was on the right.

There is, moreover, a case on record to which I have not hitherto referred, because I have been unable to see the full report of the symptoms, though I entertain no doubt it was one of lesion of the cervical sympathetic. From the remarks made about it in the work of the American surgeons ${ }^{2}$ it would seem to have presented phenomena very closely resembling those noticed in my patient. An officer was wounded on the right side of the neck; he suffered from slight ptosis of the right eye, with contraction of the pupil, and imperfect vision. Whether there was hyperæmia in the early period after the injury I do not know. Two years later, however, there was no unilateral flush; "but there was a marked defect in the secretion of sweat on the side of the lesion extending to the neck, arm, and chest, while on the left side, which was not wounded, the secretion was perhaps excessive in amount."'3

Of the remaining symptoms in my patient, positive or negative, but little need be said. I would, however, point out that, though the hyperæmia had persisted for more than two

1 I have lately seen an illustration of this. A man had the common carotid tied on the right side of the neck. Two days after the operation I found his left cheek and bone bathed in sweat, the right side quite dry.

2 Cf. op. cit., p. 44 and 86.

3 Cf. op. cit., p. 86. If the arm was really affected as well as the neck, it would seem that there must have been some other lesion than one of the cervical sympathetic. The right arm in my patient sweated. It is true that in the man's opinion it did not sweat quite so freely as did the left; but this slight difference can be explained by the difference of vascularity in the two arms ; for it will be remembered that the circulation in the right arm was carried on under difficulties. 
years, no inflammatory process had been set up. This is in accordance with the results of experimentation. Inflam. mation after section of vaso-motor nerves only occurs when either the animal is in an enfeebled state or when the hyperæmic parts are subjected to undue irritation.

Less consistent with experiment was the utter absence of hypertrophy. Neither in facial bones nor in facial muscles could I detect any increase of bulk ; though in Schiff's experiments the former, and in Benedikt's the latter were noticed to become hypertrophied. It must, however, be remembered, that the man had already reached middle age; and that it is chiefly, if not solely, in young and growing organisms that hypertrophy follows on nerve-section.

I would also call attention to the fact that the pulse was always rapid, never below 90 in the minute. It is quite possible that this rapidity was not directly connected with the nerve lesion in the neck. Still the experiments of v. Bezold ${ }^{1}$ show that, though section of the cervical sympathetic usually retards the heart's action, this result is not a constant one, but that in a certain minority of cases the contrary effect is produced and the action accelerated.

In conclusion, I would say that I cannot but believe that cases similar to the one $I$ have described will be found to be not very uncommon. Contraction of the pupil coincident with cervical tumour is of very frequent occurrence. The usual explanation of these cases is, that the tumour presses on the sympathetic, and by its pressure paralyses the action of those nerve filaments which govern the dilator muscle of the iris. In order to explain the absence of hyperæmia it is assumed that the vaso-motor filaments lie in the central part of the sympathetic nerve, while those of the iris lie on its surface, and that thus the pressure is able to act on these latter, while the more deeply seated filaments escape. ${ }^{2}$ When we

1 Cf. Funke's ' Phys.,' ii, 674, 4th edition.

2 "Es scheint dass die oculopupillären Nervenrohren im Faserstrang des Halssympathicus am meisten peripherisch gelagert sein müssen, da bei der Compression durch Tumoren die Functionsstörungen im Gebiete jener Fasergruppe weit constanter und mit grösserer Intensität auftreten als in der vasomo- 
consider what is the size and nature of the cervical sympathetic, and also how frequently the phenomenon in question occurs, it is difficult to admit this explanation. We might, indeed, conceive of slight pressure which should be sufficient to stimulate the superficial filaments without affecting the deeper ones; but how the pressure can be sufficient practically to destroy the superficial fibres, and this permanently, and yet in no way affect the rest, it is hard to imagine. That such an occurrence should be a common one it is impossible to admit.

I think that it will be found that in some of these cases the vaso-motor filaments are affected, and that the hyperæmia has been diminished by lapse of time, until it has either altogether vanished, or until, as in my patient, it has become so slight as very easily to escape notice; while in many others it will be found that the sympathetic nerve is altogether unaffected, and that the contraction of the pupil is due to pressure exercised on the jugular veins. ${ }^{1}$ For that such compression may produce contraction is abundantly plain from the interesting experiments of Kussmaul on the influence of the circulation upon the size of the pupil.

torischen und trophischen Faserbündeln des Kopftheils."-Eulenberg und Guttmann, 'Archiv fur Psychiatrie,' i, 422.

1 Cf. Kussmaul, ' Einfluss der Blutströmung auf die Iris,' \&c., 1855, p. 28. 